\title{
Moving Forward In Acculturation Research By Integrating Insights From Cultural Psychology
}

\author{
Marina M. Doucerain ${ }^{* 1}$ \\ ${ }^{1}$ Université du Québec à Montréal \\ This is a pre-copyedited, author-produced version of an article accepted for publication following peer review. The final \\ published version is available online with the following doi: 10.1016/j.ijintrel.2019.07.010 \\ This work is licensed under the Creative Commons Attribution-NonCommercial-NoDerivs 2.5 Canada License. To view a \\ copy of this license, visit http://creativecommons.org/licenses/by-nc-nd/2.5/ca/ or send a letter to Creative Commons, PO \\ Box 1866, Mountain View, CA 94042, USA.
}

\begin{abstract}
'Psychological acculturation' refers to the intra-individual change process resulting from sustained contact with a new culture, and has traditionally been researched by cross-cultural psychologists. As acculturation research has faced numerous critiques in recent years, this manuscript considers how insights from cultural psychology could help advance this field. Specifically, the three main features of the dominant acculturation conceptual framework ("what changes during acculturation", "how people acculturate", and "how well people adapt to acculturation”) are reviewed and questioned in light of research findings and recent theoretical perspectives from cultural psychology. The approach to acculturation research articulated here views cultural engagement as plural, dynamic, tacit, and centered around the acquisition and flexible use of cultural schemas. By being attuned to their cultural environment, people typically and implicitly respond in culturally appropriate ways. This experience of "cultural fluency" is disrupted when people move to a new cultural environment. Acculturation consists of the creation and flexible use of new cultural schemas (development of multicultural mind) and of changes in people's self-positioning with respect to their different cultural traditions (development of multicultural self). In doing so, they re-establish "cultural fluency" in their new cultural environment, which also influences long-term adaptation by promoting cultural fit between people and their cultural environment.
\end{abstract}

Keywords: acculturation, cultural schemas, cultural fluency, multicultural mind, multicultural self, cultural fit, implicit learning processes

\section{Introduction}

Psychological acculturation refers to the change process that people undergo as a result of prolonged exposure to a cultural environment different from the one in which they had been socialized (Redfield, Linton, \& Herskovits, 1936; Ward \& Geeraert, 2016). As such, acculturation is central to inquiries on the interplay between culture and

*Correspondence concerning this article should be addressed to Marina M. Doucerain, Department of Psychology, Université du Québec à Montréal, C.P. 8888, Succursale Centre-Ville, Montréal (QC) Canada H3C 3P8; email: doucerain.marina@uqam.ca. The author wishes to thank Andrew Ryder and Jozefien De Leersnyder for their insightful comments on an earlier version of this manuscript. 
psyche. Over time, a range of more or less coherent theoretical perspectives on this interplay has coalesced, with cross-cultural psychology (sometimes called the cultural-comparative approach) and cultural psychology currently representing the most prominent ones (Berry, Poortinga, Segall, \& Dasen, 2011). They both share a common concern with understanding the interplay between culture and psyche, but differ somewhat in their emphasis, conception of culture, and preferred methodological approaches. Compared to their cross-cultural counterparts, cultural psychologists tend to locate culture more "in the head" than "out in the world," as will be described in more detail later.

Between these two perspectives, cross-cultural psychology has been particularly dominant in the development of acculturation research, both theoretically and empirically. With anthropological roots dating back to the $19^{\text {th }}$ century, acculturation research has picked up pace over the last few decades and is now a prolific field of inquiry. However, in recent years, this research has faced an increasing number of critiques, so innovative ways to look at acculturation may be welcome. As a step in this direction, this review considers how insights from cultural psychology, a close neighbor of cross-cultural psychology, could enrich our understanding of acculturation (see also Mesquita, De Leersnyder, \& Jasini, 2017). Many critiques of acculturation research revolve around the lack of attention to culture and to dynamic and contextual aspects of acculturation, so cultural psychology, which emphasizes context and views culture as dynamic, may be a particularly fruitful source of inspiration. Specifically, I review the main features of the dominant acculturation framework in light of cultural psychological findings and theoretical perspectives, and propose to conceptualize acculturation as the reestablishment of chronic "cultural fluency” in a new cultural environment (Mourey, Lam, \& Oyserman, 2015; Oyserman, 2011).

\section{Traditional Research On Psychological Acculturation}

Acculturative changes can be extensive. Beyond finding a job and a place to live, migrants usually need to acquire a new language, learn new social norms, form new social relationships, and renegotiate their social identities. With growing levels of international migration, acculturation is a common phenomenon in many societies. For instance, $28 \%$ of the population in Australia and $20 \%$ of the population in Canada are foreign born (OECD, 2014). Research on acculturation has gained prominence during the last few decades and has been dominated by John W. Berry and colleagues' stress-coping conceptual framework (Berry, 1980, 2005 - see also Searle \& Ward, 1990 and Ward, 2001 for classic conceptualisations of acculturation). This framework includes three features, as described by Sam and Berry (2010) in a synthesis review: (1) what changes during acculturation; (2) how people acculturate; and (3) how well people adapt to acculturative changes.

"What changes during acculturation" is varied and far-reaching, is typically organized into three categories (Schwartz, Unger, Zamboanga, \& Szapocznik, 2010): cultural practices (e.g., behaviors such as food use; cultural traditions); cultural values (e.g., belief systems such as individualism or collectivism); and cultural identifications (e.g., inclusion of cultural groups into the self-concept). "How people acculturate" refers to the mechanisms leading to acculturative changes, and is typically examined through people's acculturation strategies (Berry, 1980). These strategies reflect migrants' stance toward two issues: to what extent they wish to maintain their heritage culture, such as Russian in the case of a Russian migrant to Canada, and to what extent they wish to adopt the mainstream culture, i.e., Canadian in this example. Crossing stances toward these two issues yields four strategies: integration (high heritage maintenance and mainstream adoption), assimilation (high mainstream adoption only), separation (high heritage maintenance only) and marginalization (neither heritage maintenance nor mainstream adoption). Of these four strategies, integration is typically endorsed most often (Berry, 2003). However, research has shown that a typological approach focusing on these four strategies is psychometrically unsound, and that it is preferable to focus on the two underlying mainstream and heritage cultural orientations (Demes \& Geeraert, 2014; Rudmin \& Ahmadzadeh, 2001). Finally, concerning "how well people adapt to acculturative changes," acculturation research typically focuses on the long-term impact of acculturative changes on psychological adaptation, or emotional and psychological well-being, and sociocultural 
adaptation, or the successful acquisition of practical competencies (Searle \& Ward, 1990). The relation between migrants' acculturation strategies and these two varieties of adjustment has been a core issue in acculturation research, generating a substantial number of studies. In the dominant acculturation conceptual framework, the integration strategy is thought to be the most adaptive, and a meta-analysis provided evidence of a positive relation between integration and adaptation (Nguyen \& Benet-Martínez, 2013). It should be noted that these three features of the dominant acculturation framework overlap to some extent, as some acculturative changes could also be seen as forms of adaptation in the new society (e.g., mainstream language proficiency). These three features are therefore more convenient conceptual signposts than airtight categories.

In recent years, acculturation research has been the object of substantial and sustained critiques, both on conceptual and methodological grounds. For example, critics argue that the dominant theoretical framework of acculturation, as reviewed above, may be too simplistic and underspecified. They point out that this framework is very much silent on the specific mechanisms of change (Ward, 2008; Ward \& Geeraert, 2016) and ask what integration really means, or, in other words, how a person goes about managing several cultural traditions in daily life (Boski, 2008; Ward \& Kus, 2012). Reviewing these critiques, which have been brought forward in several publications (Hunt, Schneider, \& Comer, 2004; Lopez-Class, Castro, \& Ramirez, 2011; Schwartz et al., 2010; Ward \& Geeraert, 2016), is beyond the scope of the current work. Nonetheless, they underscore the need to seek fresh perspectives on acculturation. As acculturation research has typically been conducted by crosscultural psychologists, one approach might be to consider "theoretical neighbors.” Researchers studying personculture relations have adopted different theoretical orientations, and this manuscript reviews how research conducted by cultural psychologists - with a perspective somewhat different from that of cross-cultural psychologists, as described below - could inform our understanding of acculturation.

\section{Interpretive Perspectives On Person-culture Relations}

Cross-cultural psychology typically rests on a stance of moderate universalism (Berry et al., 2011), with culture as an external factor whose influence remains at the surface level and is limited to the development and expression of human characteristics. At the core of this approach is the intellectual project of removing cultural layers to lay bare the "psychic unity of mankind" (Segall, Lonner, \& Berry, 1998; Shweder, 1990), an approach that has been likened to "peeling an onion," in order to reveal a universal psychological core. In contrast, cultural psychology is premised on the idea that culture and mind "make each other up" (Shweder, 1990, p. 24) - that is, that they define and constitute each other in given contexts. This perspective, characterized by moderate relativism, emphasizes psychological diversity and contends that different minds emerge in different cultural environments (Berry et al., 2011). In other words, culture shapes human existence so fundamentally that it is impossible to disentangle psychological processes from their cultural composition. There is no primacy of human nature to be later outfitted by culture. Or, to repeat a culinary analogy that has sometimes been used in this context, culture is not mere icing on a universal psychological cake but a key ingredient of that cake.

Cross-cultural and cultural psychology can be seen as close relatives (Adamopoulos \& Lonner, 2001), with differing emphases rather than foundations (Triandis, 2007) - although they are often presented as distinct branches by texts on the interplay between psychology and culture (e.g., Adamopoulos \& Lonner, 2001; Berry et al., 2011; Keller, 2012; Licata \& Heine, 2012). In brief ${ }^{1}$, compared to cross-cultural psychologists, cultural psychologists tend to emphasize context more than content, to see culture as more inside rather than outside the person, and to examine less stable attributes of culture rather than more stable ones (Triandis, 2007). These two perspectives also have diverging methodological leanings: cultural psychologists are more likely to use social experimental or ethnographic methods rather than self-report questionnaires and to collect data in very few rather than in many cultural contexts (Saroglou \& Cohen, 2011; Triandis, 2007). These different emphases seem

1The interested reader is directed to the chapter by Adamopoulos and Lonner (2001) for an extensive analysis of the differences between cross-cultural and cultural psychology. 
reconcilable, and indeed researchers have called for an integration of both perspectives (Keller, 2012; Triandis, 2007), which would capitalize on their complementary strengths (Adamopoulos \& Lonner, 2001).

\section{Defining Culture}

As the above sketch of cross-cultural and cultural psychology shows, differences between these two perspectives largely reflect variations in how culture is understood. Providing an explicit conceptualization of culture is therefore essential before reviewing how a cultural psychology perspective could inform acculturation research. In line with this perspective, culture is defined here as set of meanings (Geertz, 1973; Kashima \& Gelfand, 2012; Miller, 1999), that are shared to some degree, consensual to some degree, socially transmitted within a collection of individuals, and that on the whole serve the purpose of coordinating collective living (Chiu, Leung, \& Hong, 2010). These meanings are internalized as loosely organized, interconnected, and domain-specific cultural schemas rather than as a comprehensive, internally consistent, and integrated frame or worldview (Hong, Morris, Chiu, \& Benet-Martínez, 2000, p. 711). Please note that cultural schemas are used here as a generic term for cultural knowledge structures such as practices or implicit theories (Casson, 1983; D’Andrade, 1981). Of all cultural meanings available in her sociocultural environment, a person will only internalize a subset as cultural schemas (Morris, Chiu, \& Liu, 2015; Newson, Richerson, \& Boyd, 2007); and at any moment in time, only a subset of these internalized cultural schemas will be activated, depending on the demands of the situation and the person's goals (Hong et al., 2000; Weber \& Morris, 2010). Importantly, culture has a tacit quality to it: cultural schemas are almost entirely unnoticed and taken for granted by the minds that rely on them (Markus \& Hamedani, 2007; Oyserman, 2011). There are many definitions of culture, and while all cultural psychologists may not agree with this exact formulation, this definition is expected to reflect a consensus among most of them. This conceptualization will also serve as a lens to critically examine existing acculturation research.

\section{Cultural Psychology And Multiculturalism}

Since the turn of the century, cultural psychologists have been increasingly interested in how people psychologically handle multiple cultural streams, focusing on multiculturalism - the experience of having internalized more than one cultural stream - rather than on acculturation. Research on acculturation vs. multiculturals focus on closely related but somewhat different phenomena. Whereas acculturation reflects changes resulting from living in a new cultural environment after having first been socialized in a different one, multiculturalism is more suitable to describe the experience of people from cultural minorities, with mixed ethnicities, or children of immigrants (Huynh, Nguyen, \& Benet-Martínez, 2011, p. 837). Simply put, the former focuses more on the journey, the latter more on the destination. In the dominant conceptual framework of multiculturalism, multiculturalism encompasses both multicultural mind, or the knowledge and flexible use of multiple cultural traditions, and multicultural self, or the internalization of multiple cultural traditions within one’s self (Hong, Wan, Sun, \& Chiu, 2007; Wan, Dach-Gruschow, No, \& Hong, 2010). Importantly, having at one's disposal and using cultural schemas from a given cultural tradition (mind) does not entail identifying with it (self).

The next section uses insights from this work on multiculturalism and cultural psychology more broadly, to critically examine traditional acculturation research. The review will be structured according to the three features of the dominant acculturation framework: (1) what changes during acculturation; (2) how people acculturate; and (3) how well people adapt to acculturative changes. 


\section{Acculturation Research Through A Cultural Psychology Lens}

\section{What Changes During Acculturation}

Beyond practices, identifications, and values. Acculturation research has traditionally limited its scope to explicit types of acculturative changes. People are consciously aware of their cultural practices, identifications, and values, and can readily answer direct questions about changes in these categories. This overall focus on explicit changes is consistent with a methodological predilection for attitudinal self-report questionnaires in acculturation research (Doucerain, Segalowitz, \& Ryder, 2017), where people typically rate their endorsement of items such as "being American plays an important part in my life" (Birman \& Trickett, 2001) or "I believe in the values of my heritage culture" (Ryder, Alden, \& Paulhus, 2000). As a result, a special issue on critical acculturation psychology (Chirkov, 2009a) concluded that, unfortunately, acculturation research largely focuses on surface-level aspects "like language, cuisine, fashions, and other preferences, while ignoring deep meaninggenerating aspects of culture” (Chirkov, 2009b, p. 178).

In contrast, cultural psychology has argued and shown that different cultural contexts promote and foster distinct self-construals (Markus \& Kitayama, 1991), emotion patterns (Mesquita, 2001), cognitive styles (Norenzayan, Smith, Kim, \& Nisbett, 2002), etc. - in other words, different ways of being and acting in the world. This raises the possibility that beyond "surface-level" aspects such as practices and identifications, acculturation could change the cultural schemas underlying these ways of being and acting in the world (De Leersnyder, 2014; De Leersnyder, Mesquita, \& Kim, 2011, pp. 452 \& 462) - many of which, reflecting culture’s tacit quality, are largely imperceptible to people. Thus, as proposed by Mesquita and colleagues (Mesquita et al., 2017), cultural psychology's findings on different psyches emerging in different contexts suggest that "what changes during acculturation" could extend beyond explicit, surface-level aspects to include implicit, more profound changes in all domains of psychological functioning, including perception, cognition, emotion, motivation, etc.

A few studies support this extended scope of how we understand acculturative changes. Consider the domain of emotions. People tend to experience similar patterns of emotions within a given cultural context, in ways that reflect cultural values and priorities. For example, North Americans of European descent experience socially disengaging emotions such as anger and pride more frequently and more intensely than Japanese - and vice versa for socially engaging emotions such as shame and indebtedness (Kitayama, Mesquita, \& Karasawa, 2006). De Leersnyder and colleagues showed that as migrants spent more time in their new country, the pattern of emotions they experience in daily life grew more similar to the average emotional pattern of people in the mainstream society (De Leersnyder, Mesquita, \& Kim, 2011). Analogous results were found in the personality domain. The personality of Japanese migrants to the United States who reported higher participation in the US society was more similar to the average US personality pattern (measured through profile correlations with a reference US sample) than that of migrants who reported lower US cultural engagement (Güngör et al., 2013).

In the cognitive domain, Americans living in Japan incorporated more contextual information when judging the length of a line than Americans living in the U.S., thus approximating a typically Asian cognitive characteristic (Kitayama, Duffy, Kawamura, \& Larsen, 2003). Color perception may also be subject to change during acculturation. English has a single monolexemic term - blue - to describe the blue region of colour space, whereas Greek uses two such terms to divide the blue space into two distinct areas: ghalazio (space with lighter shade) and ble (space with darker shade). In a study of Greeks living in the United Kingdom, Athanasopoulos found that participants who had lived in the country for longer experienced greater distortions in their perception of the differences between the two categories of blue than more recent immigrants (Athanasopoulos, 2009).

Together, these findings show that "what changes during acculturation” goes beyond surface-level, explicit aspects such as practices and identification, and suggest extending the traditionally limited scope of acculturative changes that are considered. Acculturation does involve a renegotiation of migrants' explicit self-positioning toward their relevant cultures through changes in cultural practices, identifications, and values. In addition, it 
also entails acquiring a new set of cultural schemas guiding migrants' perception, cognition, emotion, motivation, etc. in their new cultural environment (Mesquita et al., 2017). This extended twofold scope of acculturative changes - explicit self-positioning and more "implicit" cultural schemas - maps on well to the distinction between multicultural self and multicultural mind drawn by the multiculturalism conceptual framework in cultural psychology. Thus, acculturation can be seen as the development of both a multicultural self, reflecting changes in migrants' explicit cultural self-positioning (the traditional purview of acculturation research) and a multicultural mind, reflecting the acquisition of new domain-specific cultural schemas.

Acculturation theory and research recognize that migrants experience changes in different domains, and generally assume that changes in practices, identifications, or values occur independently and at different rates (Schwartz et al., 2010). However, the interrelations among these changes have been little explored. For example, do changes in cultural identities depend on changes in cultural practices? Or from a cultural psychology perspective, are multicultural mind and multicultural self interrelated? Among monoculturals, knowledge and use of a particular cultural schema, reflecting one's cultural mind, is related to some extent to how a person explicitly positions herself with respect to her cultural tradition, which reflects one's cultural self. For example, some research has shown that Chinese people with depression tend to emphasize somatic symptoms relative to their counterparts from North America (Ryder et al., 2008), reflecting reliance on specific schemas guiding culturally-appropriate ways of expressing mental illness (Ryder, Ban, \& Chentsova-Dutton, 2011). However, Chang and colleagues found that collectivism norms, a type of cultural schema, predicted somatization of depression only among "Asian” participants who identified strongly with “Asian culture” (Chang, Jetten, Cruwys, \& Haslam, 2017). These findings indicate that in this case, the content of a person's cultural self shaped the use of specific cultural schemas. Among migrants learning to negotiate multiple cultural streams, similar interplays between multicultural self and mind are also likely and will be considered in more detail later.

Contextual variation. Acculturation entails learning to navigate multiple cultural environments; for example, juggling the cultural demands of working among mainstream Canadian colleagues and of interacting with conationals at one's Russian Orthodox church. Although acculturation research has traditionally ignored such contextual aspects (Ward \& Geeraert, 2016), in recent years, a few researchers have recognized contextual variation in migrants' cultural identification and have shown that acculturation is domain-specific (Arends-Tóth \& Van de Vijver, 2003; 2004). For example, Doucerain and colleagues (Doucerain, Dere, \& Ryder, 2013) showed that throughout the day, migrants switched between mainstream, heritage, and mainstream-hybrid cultural affiliation depending on characteristics of the local context, such as the language they spoke, the cultural background of their interlocutors, and the type of activity they engaged in (see also Yip, 2005; Zhang \& Noels, 2013). In line with the traditional scope of acculturation research, this work has focused on migrants' explicit self-positioning toward their relevant cultures, i.e., the development of a multicultural self.

However, culture, as conceptualized here, entails the dynamic activation of cultural schemas depending on the demands of a situation, so these contextual effects are also likely to play out in the case of migrants' developing multicultural mind. For example, Russians tend to inhibit the expression of happiness to unfamiliar others compared to friends and family (Sheldon et al., 2017), whereas North American cultural norms favor the expression of positive emotions in general (Eid \& Diener, 2001). A Russian migrant to Canada would routinely face situations calling for competing implicit cultural schemas of emotional expression. Encountering good news might call for a neutral face at her Russian Orthodox church, whereas a broad smile might be more appropriate among mainstream Canadian colleagues at work.

Research in cultural psychology shows that biculturals do indeed make use of different cultural versions of domain-specific schemas according to contextual cues, a phenomenon called cultural frame switching (Hong et al., 2000). For example, when primed with American cultural icons, Chinese-Americans' cognitive style reflected the typically American style, and vice-versa when primed with Chinese cultural icons (Hong et al., 2000). There is now evidence that cultural frame switching occurs in a variety of domains, such as decisionmaking (Briley, Morris, \& Simonson, 2005), emotions (Perunovic, Heller, \& Rafaeli, 2007), and personality 
(Ramírez-Esparza, Gosling, Benet-Martínez, Potter, \& Pennebaker, 2006). These findings suggest that acculturation comprises contextual variation not only in explicit cultural identifications but also in more implicit domains, such as emotion or cognition. Thus, in addition to the development of a multicultural self and multicultural mind, "what changes during acculturation" must include learning to flexibly use one's explicit cultural self-positioning and implicit cultural schemas in response to situational demands. In other words, acquiring new tools is only half the story. Acculturation also includes learning to use these tools effectively.

As mentioned earlier, a person's cultural self can shape the use of specific cultural schemas. For example, keeping a neutral face when encountering good news at one's Russian Orthodox church might be the culturally appropriate thing to do, but if a migrant wishes to convey a self-position at odds with her Russian heritage, then smiling broadly might align more closely with her stance. Indeed, research on Chinese-American biculturals showed that only participants who perceived their cultural identities as compatible and complementary displayed an attribution style congruent with cultural cues present in the context, i.e., they used a culturally appropriate schema. Conversely, those who perceived their cultural identities as oppositional and contradictory showed the opposite effect and displayed an attribution style incongruent with contextual cultural cues (Benet-Martínez \& Haritatos, 2005; see also Huynh et al., 2011 for a more exhaustive review). In this case, using a culturally appropriate schema was at odds with how people explicitly represented their multicultural self. These findings suggest that acculturation includes learning to use new cultural schemas in ways that are culturally appropriate and/or that convey one's cultural orientation.

This distinction between culturally appropriate and personally meaningful is important because it contributes to a conceptualization of acculturation that integrates perspectives from traditional acculturation research and cultural psychology. The former perspective emphasizes that acculturation is an agentic process of negotiating one's explicit self-position with respect to the cultural traditions relevant in one's life, through cultural practices, identifications, and endorsed values. The latter perspective emphasizes that acculturation also includes acquiring new cultural schemas without explicit conscious awareness and learning to use them flexibly (Mesquita et al., 2017). In any given situation, migrants' actions and experiences likely reflect the influence of both processes. I now turn to the mechanisms underlying these change processes.

\section{How People Acculturate}

To explain how people go about realizing the changes that take place during acculturation, acculturation researchers have typically focused on acculturation strategies (Berry, 1980), which reflect the extent to which migrants wish to maintain their heritage culture and the extent to which they wish to adopt the mainstream culture. However, acculturation theory and research have largely ignored the conditions that lead to the adoption of these strategies, or that trigger the need for acculturative changes in the first place.

The concept of cultural fluency may be helpful here. The set of cultural schemas people have at their disposal and selectively activate is typically "good enough" for daily functioning (Oyserman, 2011). That is, people's cultural knowledge is sufficiently aligned with their cultural environment that in any given situation they will typically know what to do and what to expect without needing to think about it (Mourey et al., 2015). For example, a French person usually knows intuitively whether to kiss the cheeks or shake the hand of someone she just met. This cultural-schema-situational-demands match fosters a state of cultural fluency (Oyserman, 2011, 2017): experiencing culture as "that which goes without saying and just feels right" (Oyserman, 2011, p. 188). In contrast, cultural disfluency arises when there is a mismatch between what activated cultural schemas predict and how the situation unfolds. Mourey and colleagues (2015) tested the hypothesis that cultural fluency leads to a tacit feeling that "all is right", and therefore to behaviors reflecting positive answers to task-specific questions such as "do I want more of this" or "should I go with my gut," in contrast to a sense that "something is awry" and behaviors reflecting negative answers to these questions in the case of cultural disfluency. They found that compared to participants in conditions of cultural fluency (e.g., holiday picnic with plate decoration matching 
the holiday theme), participants in conditions of cultural disfluency (e.g., plate decoration matching the wrong holiday) put less food on their plate, reflecting a negative "gut response" to the implicit question "do I want more of this”.

Thanks to cultural schemas' ability to organize and structure one's experiences in a way that is taken for granted, experiences of cultural disfluency are typically rare among non-migrants. However, when a person moves to a new cultural environment, experiences of cultural disfluency become chronic (Mourey et al., 2015). The new cultural environment may call for cultural schemas outside those available or readily accessible to that person, and many daily situations can no longer be taken for granted (Cresswell, 2009). Now an immigrant to Canada, our French person ponders whether to kiss, embrace, or shake hands when meeting someone. I propose that this chronic disruption in cultural fluency marks the onset of acculturation and triggers the need for acculturative changes. Daily situations routinely arouse an implicit sense that something is awry and compel people to learn new cultural schemas and/or negotiate cultural practices and identifications - in other words, go through acculturative changes - to re-establish chronic cultural fluency.

This process can be formalized using Oyserman's prediction-observation match-mismatch brain model (Oyserman, 2017), an adaptation of which is shown in Figure 1. Every situation contains contextual cues (e.g., meeting an acquaintance) that activate relevant cultural schemas (proper way to greet acquaintances schema). In turn, these schemas trigger expectations about how the situation should unfold (all will be well if acquaintance is greeted with kisses on both cheeks). If the situation unfolds as expected (acquaintance kisses back and smiles), the person experiences cultural fluency (all is well), which strengthens the activated cultural schema. However, if the situation does not unfold as expected (acquaintance is startled and stiffens), the person experiences cultural disfluency (something is awry) and seeks new information (look at how others do it) to update predictions (maybe shake hands next time). Research on cultural fluency suggests that the early stages of acculturation are likely marked by the chronic repetition of the mismatch loop on the left side of this model. Chronic experiences of cultural disfluency activate mechanisms that fit, broadly speaking, in the category "how people acculturate" and that are represented by the top left box Add new information in Figure 1. In turn, these mechanisms bring about "what changes during acculturation," in the form of multicultural mind and self development. These effects are represented by the left downward arrow from Add new information to Cultural schemas in Figure 1. Over time, as people acquire and learn to use new cultural schemas, they are better able to generate predictions that match situations, and their experience gradually shifts to the loop on the right side of the model. In short, acculturation can be seen as the process of reestablishing chronic cultural fluency.

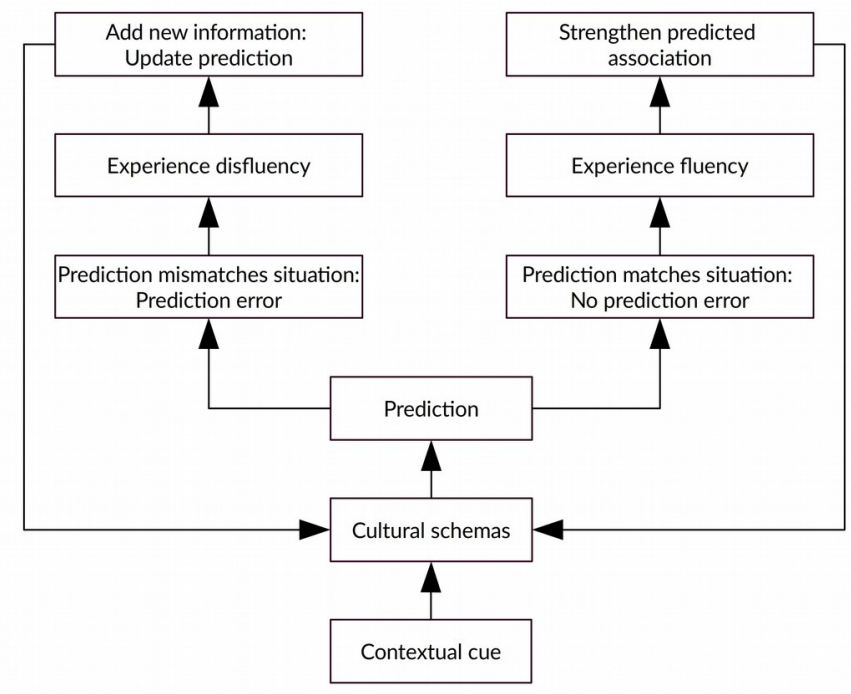

Figure 1. Acculturation and cultural fluency/disfluency. Adapted from Oyserman's (2017) prediction-observation matchmismatch brain model. 
Acculturative mechanisms. In broad brush-strokes, acculturation strategies can be seen as acculturation research's version of the box Add new information: Update prediction. However, given their largely attitudinal/ motivational nature, acculturation strategies are limited in explaining precisely how migrants acquire new cultural schemas promoting cultural fluency. Cultural psychological research on cultural conditioning may be helpful in that respect. Savani and colleagues (Savani, Morris, Naidu, Kumar, \& Berlia, 2011) showed that Indians' greater tendency to accommodate others when making decisions (compared to Americans) was tied to two aspects: influence situations tend to be more rewarding of accommodation in India than in the U.S.; and people expect accommodation to yield more positive consequences in Indian vs. American situations. In brief, they showed that people's default accommodation decision, or accommodation cultural schema, reflect lifelong conditioning by cultural contexts that afford or constrain different accommodation styles. Importantly, they also found that as participants were experimentally exposed to situations from the other culture, their accommodation style gradually converged toward that of the other culture, reflecting attunement to a reward pattern different from that of their own culture.

These findings reinforce the idea that cultural schemas are malleable, and suggest that migrants may acquire new cultural schemas through similar cultural conditioning mechanisms (Mesquita et al., 2017). Experiencing cultural disfluency has been shown to shift processing from associative to rule-based systematic processing (Mourey et al., 2015), which may induce migrants to pay even closer attention to what is rewarded in the new cultural environment. As migrants notice and try out culturally sanctioned ways of being and acting, they are socially rewarded, which in turn increases the likelihood of responding in culturally congruent ways the next time around. Over time, these new patterns and tendencies become internalized in cultural schemas.

Consistent with Bandura's theory of observational learning, cultural conditioning and the acquisition of new cultural schemas more broadly, may not require first-hand experience of situations. Kashima and colleagues (2015) investigated cultural transmission mechanisms in the context of artificial "microcultures" in the laboratory and found that newcomers to the culture learned implicit cultural attitudes by observing old-timers' performance and inferring their attitudes (positive/negative evaluation of stimuli). In contrast, newcomers learned cultural practices through explicit instructions and imitation. Along with Savani and colleagues' (2011) work on accommodation, these results suggest that by engaging directly or indirectly in the new cultural environment, migrants gain new cultural information about what is desirable or unwelcome in given situations and are rewarded for acting in culturally congruent ways. Thus, the acquisition of new cultural schemas may take place largely through implicit learning processes such as cultural conditioning and observational learning (Mesquita et al., 2017; Morris, Chiu, \& Liu, 2015).

Observational learning may be particularly effective in the case of migrants, as it may circumvent the limits of intercultural interactions. During one-on-one intercultural interactions, the mainstream interlocutor might unwittingly adjust his conduct to accommodate the migrant's assumed-to-be-limited cultural proficiency. In contrast, observing behaviors of members of the mainstream cultural group may afford greater access to unmodified, natural cultural representations and therefore facilitate the learning of "authentic" cultural schemas (Doucerain, Varnaamkhaasti, Segalowitz, \& Ryder, 2015). As such, observational learning may provide some access to intracultural cultural transmission channels. Indeed, there is evidence that at least one type of communication pragmatics tied to cultural meaning transmission differs between intracultural and intercultural communication contexts. Within-culture, when sharing a story, people tended to transmit more stereotypeconsistent than inconsistent information, which serves a social connectivity function and incidentally creates and perpetuates cultural representations (Lyons \& Kashima, 2006). However, with similar methods, this effect disappeared in conditions of intercultural communication: when sharing a story with someone from a different cultural group, people shared equal proportions of stereotype-consistent and inconsistent information (Liu \& Morris, 2014), suggesting that cultural transmission may function differently via intercultural vs. intracultural interactions. To the extent that it circumvents these issues, observational learning may be a key mechanism underlying acculturative changes such as cultural schemas acquisition. 
Kashima and colleagues' (2015) work on “microcultures” suggest that explicit processes (imitation and instruction in their case) also have a role to play in learning new cultural practices, and therefore in acculturation. This notion is consistent with acculturation researchers' emphasis on the role of acculturation strategies, which reflect migrants' explicit preferences regarding how to engage with their cultural traditions. Thus, both implicit learning processes and explicit strategies are likely involved in bringing about acculturative changes. Interactions between these two types of mechanisms are also plausible; two examples of such interactions are considered below.

Interplay between acculturation strategies and implicit cultural learning processes. Recognizing the critical role of contact and interactions with members of the mainstream cultural group, acculturation researchers recently proposed that acculturation strategies direct migrants' attention and efforts in certain directions, influencing, in turn, the likelihood of certain types of social interactions taking place (Doucerain, Deschênes, Gouin, Amiot, \& Ryder, 2017). An aggregation of small decisions motivated by migrants' acculturation strategies, such as where to shop, where to live, or whom to address, shapes the social makeup of their daily life, and therefore the type of situations and cultural meanings that will be sampled in the box Add new information: Update prediction in Figure 1. Consistent with this role of acculturation strategies, among migrants just arrived in a new country, more positive initial orientation toward the mainstream cultural group (a component of acculturation strategies) prospectively predicted greater social engagement (number of friends, number of regular interlocutors) in the mainstream cultural group over time, controlling for a number of important alternative predictors (Doucerain, Deschênes, et al., 2017). These findings suggest that explicit acculturation strategies may interact with implicit cultural learning processes by shaping migrants' local cultural ecology (Segalowitz, Gatbonton, \& Trofimovich, 2009), thus affording and constraining what type of, and the extent to which implicit learning processes can take place.

Beyond influencing whether they will take place, acculturation strategies may also affect how implicit learning processes play out during social interactions. Kwan and colleagues (Kwan, Yap, \& Chiu, 2015) showed that people learned new descriptive norms over time through mere exposure to a culture and without being taught explicitly, which is consistent with Savani et al.'s (2011) findings on cultural conditioning. However, these newly learned norms were tied to participants' preferences, a form of internalization, only among participants for whom a need for connectedness with the group had been induced. Given the conceptual similarities between descriptive norms and cultural schemas, and between acculturation strategies and need for connectedness with a group, these findings suggest that in a given social situation, cultural conditioning and other implicit learning processes may not be equally effective among all migrants. The learning and internalization of a new cultural schema during social engagement may require, or at least be facilitated by, positive orientation toward the cultural group in question. In other words, acculturative strategies may act as a lens that filters what cultural meanings are processed in a given situation (box Add new information: Update prediction in Figure 1) and to what extent these meanings are internalized as cultural schemas (left downward arrow from Add new information to Cultural schemas in Figure 1).

\section{How Well People Adapt To Acculturative Changes}

As mentioned earlier, a significant proportion of acculturation research has focused on the association between acculturation strategies and sociocultural and psychological adaptation, with the general conclusion that integration is most adaptive (Nguyen \& Benet-Martínez, 2013). Although this research has been almost exclusively cross-sectional, acculturation theory tacitly assumes that acculturation strategies, and integration in particular, exert causal influence on adaptation (Rudmin, 2009). Presuming for a moment that this is indeed the case, we know very little about the mechanisms underlying this effect. Work on cultural fit from cultural psychology may help shed some light on this issue.

"Fitting in" with a cultural context. Cultural fit refers to the extent to which people's own ways of feeling, 
thinking, and behaving are congruent with the psychological tendencies that are valued, promoted, and rewarded by their cultural context. Across a range of domains and contexts, people who display greater cultural fit report more well-being (De Leersnyder, Kim, \& Mesquita, 2015; De Leersnyder, Mesquita, Kim, Eom, \& Choi, 2014; Dressler, Balieiro, Santos, \& Ernesto, in press; Kitayama, Karasawa, Curhan, Ryff, \& Markus, 2010; Townsend, Kim, \& Mesquita, 2014). For example, Americans reporting greater personal control, thus fulfilling the American cultural mandate of independence, experienced greater well-being and health. Conversely, the absence of relation strain, which is key to achieving a Japanese cultural mandate of interdependence, was the strongest predictor of well-being and health among Japanese participants (Kitayama et al., 2010). Similarly, among migrants, people whose emotional response pattern fit the average mainstream emotional pattern reported fewer somatic symptoms (Consedine, 2014), and greater fit with the mainstream culture in terms of extraversion was associated with lower levels of depression (Ward \& Chang, 1997). These findings suggest that being attuned to the mandates of one's new cultural environment, reflecting the acquisition and use of new appropriate cultural schemas, is adaptive for migrants (Mesquita et al., 2017). Although research has not yet investigated the wellbeing consequences of migrants' fit with their heritage culture, it is likely that when navigating a heritage cultural context, using cultural schemas that are valued and rewarded by that culture is also adaptive (De Leersnyder, 2014, p. 23). Thus, having at one's disposal cultural schemas that can fulfill the cultural mandates of both heritage and mainstream cultures, or being "psychological equipped for the central tasks" in these cultural contexts (Mesquita et al., 2017, p. 7), may be most adaptive, as this configuration allows migrants to meet the cultural demands of a broader range of situations.

In parallel, based on the above discussion on the relations between acculturation strategies and implicit cultural learning processes, acculturation strategies are likely to foster cultural fit by facilitating the acquisition of new cultural schemas. Consistent with this, emotional fit with one's group (comparable to cultural fit) was highest among people who identified most strongly with the group, which is conceptually close to acculturation strategies (Delvaux, Meeussen, \& Mesquita, 2015). Similarly, among Korean migrants to the U.S., positive orientation toward social engagement in the mainstream culture - a component of acculturation strategies - was positively associated with emotional fit with the mainstream culture (De Leersnyder et al., 2011). Thus, cultural fit may mediate to some extent the often-documented association between acculturation strategies and adaptation. Acculturation strategies influence implicit cultural learning processes that foster the acquisition of new cultural schemas, thus promoting cultural fit between migrants' psychological tendencies and surrounding cultural mandates. In turn, fulfilling these cultural mandates leads to greater adaptation.

Resources and adaptation. Drawing on Lazarus and Folkman's (1984) stress model, the dominant stress-coping framework of acculturation posits that when demands exceed migrants' resources, they experience stress (Berry, 2005), which negatively impacts adaptation. These notions of "demands," "resources," and "stress," are fairly imprecise, and work on cultural fluency may help address this lack of precision.

In their investigations of the consequences of cultural fluency/disfluency, Mourey and colleagues (Mourey et al., 2015) showed that experiencing cultural disfluency, for example when facing a green rather than white wedding dress, prompted a shift from automatic and effortless to systematic and effortful processing, reflecting an implicit sense that something is awry and that the situation needs to be attended to more carefully. Cognitive capacity the energy available to process information - is limited (Kahneman, 1973), and different processes tap into this mental energy to various degrees. Whereas automatic processing requires very little cognitive capacity, systematic processing is highly demanding in terms of attentional capacity and depletes cognitive resources (Hasher \& Zacks, 1979; Shiffrin \& Schneider, 1977). Thus, "people consume a global but limited resource when they override habitual or natural responses” (Vohs, Baumeister, \& Ciarocco, 2005, p. 632); in other words, when they experience cultural disfluency. As discussed earlier, the early stages of acculturation are marked by chronic experiences of cultural disfluency, and therefore by chronic reliance on systematic, effortful processing, which is taxing (Mourey et al., 2015). In turn, relying primarily on this type of processing may routinely exhaust migrants' limited mental energy, thus leading to stress and risks of poorer adaptation. 
This perspective on the "mental cost" of acculturation may also shed some light on the assumed causal effect of acculturation strategies on adaptation. Upon experiencing chronic cultural disfluency in mainstream cultural contexts, newly arrived migrants face two choices. They could favor heritage cultural contexts, which rely on existing heritage cultural schemas, and therefore limit experiences of cultural disfluency. This pattern of preferences, reflecting a separation acculturation strategy, promotes automatic processing and is therefore mentally less costly. On the other hand, migrants may adopt an integration or assimilation strategy, and seek out mainstream social engagement. At first, given the lack of relevant cultural schemas, this approach may exacerbate experiences of cultural disfluency and routinely exhaust migrants' limited mental energy, thus leading to stress. In the short term, the relation between integration and adjustment may be negative, and acculturative changes may be limited by how much mental energy is available. This would be consistent with the untested suggestion that "the often claimed correlation between biculturalism and low stress may not be a consequence of biculturalism but a consequence of highly stressed people avoiding biculturalism because of "the extra conflict and diversity-related stress that this acculturation strategy produces” (Luijters, van der Zee, \& Otten, 2006, p. 561)” (Rudmin, 2009, p. 115). Indeed, in a longitudinal study of newly arrived migrants, initial psychological and sociocultural adjustment combined predicted greater adoption of the mainstream culture over the following year, but not vice-versa (Ryder, Doucerain, \& Amiot, 2017).

However, as migrants engage in the mainstream culture and learn new cultural schemas through cultural conditioning and related learning processes, they progressively experience cultural fluency more regularly, and thus gradually shift to automatic, effortless processing, which preserves migrants' limited mental energy. In turn, this may help alleviate stress and contribute to adaptation. So in the long term, by promoting the acquisition of cultural schemas and cultural fit in a broader range of situations, integration may lead to greater adaptation, as tacitly assumed by acculturation theory and research.

Unfortunately, for immigrant groups that are highly stigmatized and discriminated against, the type of mainstream social engagement that fosters cultural fluency may always remain psychologically costly and effortful, as the experience of prejudice during interactions likely outweighs the benefits of cultural fluency. Accordingly, in the face of high discrimination, separation as an acculturation orientation may be more conducive to adjustment than integration (Baysu, Phalet, \& Brown, 2011; Branscombe, Schmitt, \& Harvey, 1999). To sum up, the relation between acculturation strategies and adaptation may be more complicated than traditionally conceived. It may depend on the time frame studied (and/or on the immigrant group), and work on cultural fluency suggests that a more precise understanding of this relation requires considering trade-offs between short-term costs and long-term gains in mental energy, stress, and adjustment.

Other facets of adaptation. Consistent with a stress-coping framework, examinations of acculturation outcomes have traditionally been limited to sociocultural and psychological adaptation: in short, do acculturative changes impact people's ability to function practically and emotionally? However, research on multiculturalism suggests that acculturation may also accrue benefits in other domains. For example, Chinese American biculturals exhibited greater cognitive complexity in their descriptions of American and Chinese cultures than monocultural Anglo-Americans (Benet-Martínez, Lee, \& Leu, 2006). In a related vein, exposure to multicultural experiences was associated with greater creativity, both among monoculturals (Leung, Maddux, Galinsky, \& Chiu, 2008) and biculturals (Saad, Damian, Benet-Martínez, Moons, \& Robins, 2013), possibly because such experiences encourage people to consider information from different perspectives. Likewise, adolescents in Germany who experienced greater intercultural contact also displayed greater intercultural competence (Schwarzenthal, Juang, Schachner, van de Vijver \& Handrick, 2017). These findings suggest that, through the acquisition of new cultural schemas, acculturation may also foster desirable outcomes such as cognitive complexity, creativity, and intercultural competence. Beside treating acculturation as a liability and investigating what conditions limit its adverse effects, it might be worthwhile to also think of acculturation as an enriching process and consider what positive effects it might have on people. In other words, other outcomes beyond sociocultural and psychological adaptation are worth exploring. 


\section{Wrapping Up And Moving Forward}

The dominant conceptual framework guiding acculturation (Arends-Tóth \& Van de Vijver, 2006; Berry, 2003; Bourhis, Moïse, Perreault \& Senécal, 1997; Ward, 2001) posits that migrants use different acculturation strategies (how people acculturate), that bring about a range of affective, behavioral, and cognitive changes (what changes during acculturation), with more or less positive long-term psychological and sociocultural adjustment consequences (how people adapt to acculturation). This review revisited these three features from a cultural psychology perspective. In this view, acculturative changes are not limited to explicit changes in cultural practices, identifications and values (see also De Leersnyder, 2014; and Mesquita et al., 2017 for a similar view). They also include acquiring and learning to flexibly use cultural schemas guiding migrants' perception, cognition, emotion, motivation, etc. in their new cultural environment. Thus, acculturation comprises an agentic renegotiation of one's self-position with respect to relevant cultural traditions - multicultural self development and an implicit, largely unnoticed reconfiguration of the psyche in most domains of psychological functioning multicultural mind development.

These changes are initiated by chronic experiences of cultural disfluency, or situations where people's "unconscious and automatic habits of interaction, practice, and communication fail to function as a result of a changing context characterized by a different group’s symbolic organization” (Neuman, 2013). Through various implicit learning processes such as cultural conditioning and observational learning, migrants acquire new cultural schemas that allow them to meet the implicit cultural demands of the various situations they encounter. So, to a large extent, acculturation can be understood as the process of re-establishing chronic cultural fluency. Migrants' multicultural self and acculturation strategies, reflecting agentic components of acculturation, influence these implicit aspects of acculturation in several ways. They influence what cultural schemas are learned by shaping migrants' local cultural ecology and by guiding how cultural meaning is processed during cultural engagement. They also regulate the use of cultural schemas in a given situation, in ways that coordinate what is personally meaningful and culturally appropriate.

From a cultural psychology perspective, cultural fit, or being attuned to the mandates of one's cultural environment, may be a key mechanism underlying adaptation outcomes of acculturation. Having at one's disposal cultural schemas that can meet the demands of a wide range of cultural situations is adaptive, such that cultural fit may mediate the positive association between an integration acculturation strategy and adaption. However, given the high mental cost of cultural disfluency, evaluating the consequences of an integration strategy requires considering trade-offs between short-term costs of that strategy (greater exposure to unfamiliar cultural situations exacerbates cultural disfluency), and its long-term adaptation gains. Finally, it is important to not only treat acculturation as a liability for migrants' adaptation, as acculturation may also have positive effects on people, such as cognitive complexity and creativity.

Methodological implications. The acquisition of new cultural schemas plays a central role in the present conceptualization of acculturation as the reestablishment of cultural fluency. Consequently, research from this perspective requires characterizing cultural schemas in operational terms. Unfortunately, acculturation researchers have traditionally not devoted much attention to this issue. Beyond simplistic heritage vs. mainstream dichotomies, culture and cultural schemas are usually left undefined, and therefore unmeasured (Ryder \& Dere, 2010). When they happen, discussions of cultural schemas are left to implicit assumptions about differences between the cultural streams involved (Hunt et al., 2004) - for instance, the notion that familism is more central in the "Latino culture" than in the "American culture." Further, in most metropoles, sweeping generalizations about heritage vs. mainstream cultures are inadequate to characterize migrants' local cultural context. Picture for example people settling in highly a multicultural neighborhood where no national origin dominates, but where most share the experience of being immigrants. The cultural schemas internalized through living in such neighborhoods may not directly reflect a specific national culture, but they nevertheless underlie a particular cultural way of being that migrants acculturate to. For example, beyond heritage and mainstream cultural orientations, a third multicultural orientation was necessary in order to explain the psychosocial 
adaptation of migrant youth in Switzerland (Haenni Hoti, Heinzmann, Müller \& Buholzer, 2017).

Cultural psychologists are not immune to using nation-as-culture proxies, but several researchers use interesting ways to characterize cultural schemas. For example, when investigating changes in the emotional response pattern of Turkish migrants living in Belgium, De Leersnyder and colleagues first assessed typical emotional responses in daily situations in a sample of monocultural Flemish Belgians, matched to the migrant group on education and gender composition (De Leersnyder et al., 2011). Cultural fit was then operationalized as profile correlations between the average pattern in this reference group and migrants' own emotional pattern. Similarly, in their work on interpersonal accommodation, Savani and colleagues first sampled influence situations in India and the U.S., before examining participants' malleability in accommodation tendencies as they were exposed to situations from the other group (Savani et al., 2011). Studies of cultural products may provide an alternative to using reference samples that still avoids relying on implicit assumptions about cultural tendencies. Using this approach, researchers characterize cultural tendencies using tangible, public representations of culture such as advertising or popular texts (Morling \& Lamoreaux, 2008). For example, the pictures of best-selling storybooks in Taiwan and the U.S. reflected affective states respectively considered ideal in these two cultural contexts (Tsai, Louie, Chen, \& Uchida, 2007; see also Boiger, Deyne, \& Mesquita, 2013, for a similar approach in the U.S. and Belgium). Both approaches underscore the importance of obtaining detailed information on the psychological tendencies that are normative, valued, and rewarded in the cultural context that migrants acculturate to (which may or may not align with national boundaries, depending on the researcher's goal). In both cases, acculturation researchers may need to step out their self-report attitudinal scales comfort zone and consider using a broader range of methods (Doucerain, Segalowitz, et al., 2017).

Future directions. Heeding the call to integrate cultural and cross-cultural psychology perspectives (Keller, 2012; Triandis, 2007), this work reviewed how insights from cultural psychology could enrich the study of acculturation. A first important future direction would be to see more research conducted along those lines. So far, research that clearly operationalized cultural schemas and that examined "fluency" in the use of these schemas mostly focused on emotions (i.e., work on emotional acculturation). Given the prevalence of emotions in all life domains and their position at the heart of long-standing debates and research traditions in cultural and cross-cultural psychology (see e.g., Ekman \& Friesen for a more universalist perspective, or Barrett, 2007, for a more culturally-bound one), this emphasis on emotions is understandable. Yet, it would be interesting to document changes in other - maybe less central in psychological research - cultural schemas as a result of acculturation. Research on constructs that differ across cultural contexts, in psychology or in other disciplines such as anthropology or linguistics, could offer initial insights on interesting candidates. For example, Wierzbicka has provided linguistic evidence that the construct of friendship differs across languages and linguistic communities (Wierzbicka, 1997): what is expected, acceptable, or characteristic of a friend is quite different from that of a droog (direct translation of friend in Russian). Therefore, Russian immigrants to Englishspeaking countries may "import" their cultural schema of friendship and experience cultural dysfluency when attempting to use this schema in their social relationships with members of the mainstream cultural group - as supported by qualitative research of Russian immigrants to Canada (Doucerain, Benkirane, Ryder, \& Amiot, 2018). Studying how migrants' friendship schema change as they engage in the mainstream group - potentially reflecting a gradual reestablishment of cultural fluency in that domain - is an example of future acculturation research from a cultural psychology perspective. Such research would first need to operationalize friendship cultural schemas, and track changes in the friendship schema that migrants rely on. A second stage could then focus on the mechanisms that foster or hinder changes in friendship schema, such as for example certain characteristics of migrants' friendship networks (Doucerain et al., 2015). A similar approach could be applied to a wide range of cultural schemas beyond friendship.

Beyond this obvious step, considering how acculturation research might benefit cultural psychology would contribute to a fuller integration between cultural and cross-cultural psychology orientations. Doing so is beyond the scope of the present review, but thinking about the role of agentic processes and macro-level contextual variables such as discrimination and dominant ideologies, both of which feature prominently in acculturation 
research, could be a starting point. For example, Ferguson and colleagues showed that people deliberately calibrate their cultural identity during interactions in accordance with their goals (Ferguson, Nguyen, \& Iturbide, 2016), suggesting that people's volition may regulate cultural influences more than is sometimes assumed by cultural psychologists. In a related vein, the present review did not detail how some variables typical in acculturation research, such as mainstream language competence, perceived discrimination, acculturative stressors, or immigration ideologies, fit with the proposed conceptualization of acculturation as re-establishing chronic cultural fluency. In broad terms, these variables might intervene in two ways. First, they might shape to some extent the content and occurrence of implicit cultural learning processes. For example, experiencing high levels of discrimination may deplete people's limited mental energy by making them "on edge" and vigilant. In turn, this mentally depleted state may limit the effectiveness of implicit learning processes. Second, these variables might influence how migrants explicitly position themselves with respect to the relevant cultural traditions, through cultural identifications and practices. For example, a migrant who experiences high levels of discrimination may avoid social engagement with members of the mainstream culture and favor more traditional heritage apparel. In turn, this may limit his opportunities to develop cultural fluency in a broad range of cultural contexts. Nevertheless, the specific role of these variables in the reestablishment of chronic cultural fluency among migrants should be mapped out in future research.

Reflecting the emphasis of most previous acculturation research, the current review focused on migrants' acculturation. However, it would also be important in future research to study acculturative processes among members of the mainstream cultural group. They too are likely to change as a result of regular intercultural contact. The dominant and consensual mainstream cultural schemas required for daily functioning may evolve as a given society becomes increasingly multicultural, thus also challenging cultural fluency for members of the mainstream cultural group - albeit to a lesser extent than for migrants. This is consistent with a view of culture as a dynamic consensus emerging from constant and mostly implicit negotiations among people of how to function in a given society. As such the current perspective on acculturation is well aligned with recent neodiffusionist research programs on cultural dynamics (see Kashima, 2008 for a review), which could help inform future acculturation research.

Finally, the role of migrants' preexisting cultural makeup will need to be considered. Multicultural mind formation was described here in terms of new cultural schemas acquisition, but this may be an oversimplification, in particular regarding the role of preexisting cultural schemas. Do these schemas disappear, or simply change in levels of chronic accessibility? Do they change to accommodate new cultural meanings, or do new schemas need to be created altogether? How are new and old schemas organized cognitively? As a starting point to answering these questions, parallels could be drawn with the psycholinguistics literature on bilingualism (Groot \& Kroll, 2014), which examines how two different languages are represented and stored mentally. When considering this cluster of question, it might be interesting to also reflect on the role of cultural distance, or the degree of dissimilarity between the sets of cultural schemas that are dominant and consensual in two different cultural contexts. Migrants living in a society culturally close to their heritage cultural context may be able to only marginally tweak their existing cultural schemas to engage in the new society. In contrast, moving to a culturally more distant society may require more fundamental alterations of one's cultural schemas. In other words, it may be easier to reestablish cultural fluency and to achieve fit with the new cultural context when moving to a culturally less distant society.

\section{Conclusion}

Acculturation research has traditionally operated within a moderately universalist cross-cultural theoretical framework and heavily focused on migrants' acculturation strategies (variously called attitudes, orientations, strategies, preferences, identities, among other related terms; Rudmin \& Ahmadzadeh, 2001). Acculturation research has been prolific, but an increasing number of critiques and proposals to rethink acculturation have been published in recent years. This review continues in this vein and joins an emerging perspective (Mesquita et al., 
International Journal of Intercultural Relations, 2019 - NOT THE FINAL TYPESET VERSION

2017; Morris et al., 2015) that considering acculturation from a cultural psychology perspective would be fruitful: in short, to think of acculturation as re-establishing "cultural fluency" in a new cultural environment through the development of multicultural mind and self. The goal here was not to draw an exhaustive and detailed new theory of acculturation, but rather to sketch a conceptual framework to guide research in that direction. Thus, the present argument is meant primarily as a conversation starter.

There are signs that such a conversation is timely. Immigration features prominently in public discourse in most European and North American countries, and psychologists are increasingly called upon to challenge modernist views of culture as homogeneous, internally consistent and geographically bounded (Morris et al., 2015). In addition, recent research like De Leersnyder and colleagues' work on emotional acculturation (De Leersnyder et al., 2011) has already started examining acculturation from a cultural psychology standpoint. My hope with the present review is to inspire more research and theorizing on how migrants go about re-establishing cultural fluency.

\section{References}

Adamopoulos, J., \& Lonner, W. J. (2001). Culture and psychology at a crossroad: Historical perspective and theoretical analysis. In D. R. Matsumoto (Ed.), The handbook of culture \& psychology (pp. 11-34). New York, NY: Oxford University Press.

Arends-Tóth, J., \& van de Vijver, F. J. R. (2004). Domains and dimensions in acculturation: Implicit theories of TurkishDutch. International Journal of Intercultural Relations, 28(1), 19-35. doi:10.1016/j.ijintrel.2003.09.001

Arends-Tóth, J., \& Van de Vijver, F. J. R. (2006). Issues in the conceptualization and assessment of acculturation. In M. H. Bornstein \& L. R. Cote (Eds.), Acculturation and parent-child relationships: Measurement and development (pp. 3362). Mahwah, NJ: Erlbaum.

Athanasopoulos, P. (2009). Cognitive representation of colour in bilinguals: The case of Greek blues. Bilingualism: Language and Cognition, 12(01), 83-95.

Barrett, L. F. (2006). Are emotions natural kinds? Perspectives on Psychological Science, 1(1), 28-58. doi:10.1111/j.17456916.2006.00003.x

doi:10.1017/S136672890800388X

Baysu, G., Phalet, K., \& Brown, R. (2011). Dual identity as a two-edged sword: Identity threat and minority school performance. Social Psychology Quarterly, 74(2), 121-143. doi:10.1177/0190272511407619

Benet Martínez, V., \& Haritatos, J. (2005). Bicultural Identity Integration (BII): Components and psychosocial antecedents. Journal of Personality, 73(4), 1015-1050. doi:10.1111/j.1467-6494.2005.00337.x

Benet-Martínez, V., Lee, F., \& Leu, J. (2006). Biculturalism and cognitive complexity. Journal of Cross-Cultural Psychology, 37(4), 386-407. doi:10.1177/0022022106288476

Berry, J. W. (1980). Acculturation as varieties of adaptation. In A. M. Padilla (Ed.), Acculturation: Theory, models and some new findings (pp. 9-25). Boulder: Westview.

Berry, J. W. (2003). Conceptual approaches to acculturation. In K. M. Chun, P. B. Organista, \& G. Marin (Eds.), Acculturation: Advances in theory, measurement, and applied research (pp. 17-37). American Psychological Association.

Berry, J. W. (2005). Acculturation: Living successfully in two cultures. International Journal of Intercultural Relations, 29(6), 697-712. doi:10.1016/j.ijintrel.2005.07.013

Berry, J. W., Poortinga, Y. H., Segall, M. H., \& Dasen, P. R. (2011). Cross-cultural psychology: Research and applications (3rd ed.). New York, NY: Cambridge University Press.

Birman, D., \& Trickett, E. J. (2001). Cultural transitions in first-generation immigrants acculturation of soviet jewish refugee adolescents and parents. Journal of Cross-Cultural Psychology, 32(4), 456-477.

Boiger, M., Deyne, S. D., \& Mesquita, B. (2013). Emotions in "the world": Cultural practices, products, and meanings of anger and shame in two individualist cultures. Frontiers in Cultural Psychology, 4, 867. doi:10.3389/fpsyg.2013.00867

Boski, P. (2008). Five meanings of integration in acculturation research. International Journal of Intercultural Relations, 32(2), 142-153. doi:10.1016/j.ijintrel.2008.01.005

Bourhis, R. Y., Moïse, L. C., Perreault, S., \& Senécal, S. (1997). Towards an interactive acculturation model: A social psychological approach. International Journal of Psychology, 32(6), 369-386. doi:10.1080/002075997400629

Branscombe, N. R., Schmitt, M. T., \& Harvey, R. D. (1999). Perceiving pervasive discrimination among African Americans: Implications for group identification and well-being. Journal of Personality and Social Psychology, 77(1), 135-149. doi:10.1037/0022-3514.77.1.135

Briley, D. A., Morris, M. W., \& Simonson, I. (2005). Cultural chameleons: Biculturals, conformity motives, and decision making. Journal of Consumer Psychology, 15(4), 351-363.

Casson, R. W. (1983). Schemata in cognitive anthropology. Annual Review of Anthropology, 12(1), $429-462$.

Chang, M. X.-L., Jetten, J., Cruwys, T., \& Haslam, C. (2017). Cultural identity and the expression of depression: A social 
International Journal of Intercultural Relations, 2019 - NOT THE FINAL TYPESET VERSION

identity perspective. Journal of Community \& Applied Social Psychology, 27(1), 16-34. doi:10.1002/casp.2291

Chirkov, V. (Ed.). (2009a). Critical acculturation psychology. International Journal of Intercultural Relations, 33(2). doi:10.1016/j.ijintrel.2009.03.003

Chirkov, V. (2009b). Summary of the criticism and of the potential ways to improve acculturation psychology. International Journal of Intercultural Relations, 33(2), 177-180.

Chiu, C.-Y., Leung, A. K., \& Hong, Y.-Y. (2010). Cultural processes: An overview. In A. K. Leung, C. Y. Chiu, \& Y. Hong (Eds.), Cultural Processes: A Social Psychological Perspective (pp. 3-24). New York, NY: Cambridge University Press.

Consedine, N. S. C.-D., Yulia E. Krivoshekova. Yulia S. (2014). Emotional acculturation predicts better somatic health: Experiential and expressive acculturation among immigrant women from four ethnic groups. Journal of Social \& Clinical Psychology, 33(10), 867-889. doi:10.1521/jscp.2014.33.10.867

Cresswell, J. (2009). Towards a post-critical praxis: Intentional states and recommendations for change in acculturation psychology. International Journal of Intercultural Relations, 33(2), 162-172. doi:10.1016/j.ijintrel.2008.12.005

D’Andrade, R. G. (1981). The cultural part of cognition. Cognitive Science, 5(3), 179-195.

De Leersnyder, J. (2014). Emotional acculturation (Unpublished doctoral dissertation). University of Leuven, Belgium.

De Leersnyder, J., Kim, H., \& Mesquita, B. (2015). Feeling right is feeling good: psychological well-being and emotional fit with culture in autonomy- versus relatedness-promoting situations. Frontiers in Psychology, 6. doi:10.3389/fpsyg.2015.00630

De Leersnyder, J., Mesquita, B., Kim, H., Eom, K., \& Choi, H. (2014). Emotional fit with culture: A predictor of individual differences in relational well-being. Emotion, 14(2), 241-245. doi:10.1037/a0035296

De Leersnyder, J., Mesquita, B., \& Kim, H. S. (2011). Where do my emotions belong? A study of immigrants' emotional acculturation. Personality and Social Psychology Bulletin, 37(4), 451-463. doi:10.1177/0146167211399103

Delvaux, E., Meeussen, L., \& Mesquita, B. (2015). Feel like you belong: on the bidirectional link between emotional fit and group identification in task groups. Frontiers in Psychology, 6. doi:10.3389/fpsyg.2015.01106

Demes, K. A., \& Geeraert, N. (2014). Measures matter: Scales for adaptation, cultural distance, and acculturation orientation revisited. Journal of Cross-Cultural Psychology, 45(1), 91-109. doi:10.1177/0022022113487590

Doucerain, M. M., Benkirane, S., Ryder, A. G., \& Amiot, C. E. (2018). Being a droog vs. being a friend: A qualitative investigation of friendship models in Russia vs. Canada. Rossiiskii Psikho Logicheskii Zhurnal - Russian Psychological Journal, 15(2/1), 19-37. doi:10.21702/rpj.2018.2.1.2

Doucerain, M. M., Dere, J., \& Ryder, A. G. (2013). Travels in hyper-diversity: Multiculturalism and the contextual assessment of acculturation. International Journal of Intercultural Relations, 37(6), 686-699. doi:10.1016/j.ijintrel.2013.09.007

Doucerain, M. M., Deschênes, S. S., Gouin, J.-P., Amiot, C. E., \& Ryder, A. G. (2017). Initial mainstream cultural orientations predict early social participation in the mainstream cultural group. Personality and Social Psychology Bulletin, 43(2), 245-258. doi:10.1177/0146167216679642

Doucerain, M. M., Segalowitz, N., \& Ryder, A. G. (2017). Acculturation measurement: From simple proxies to sophisticated toolkit. In S. J. Schwartz \& J. Unger (Eds.), The Oxford Handbook of Acculturation and Health. New York, NY: Oxford University Press.

Doucerain, M. M., Varnaamkhaasti, R. S., Segalowitz, N., \& Ryder, A. G. (2015). Second language social networks and communication-related acculturative stress: the role of interconnectedness. Frontiers in Psychology, 6, 1111. doi:10.3389/fpsyg.2015.01111

Dressler, W. W., Balieiro, M. C., Santos, D., \& Ernesto, J. (in press). What you know, what you do, and how you feel: Cultural competence, cultural consonance, and psychological distress. Frontiers in Psychology, 8. doi:10.3389/fpsyg.2017.02355

Ekman, P., \& Friesen, W. V. (1971). Constants across cultures in the face and emotion. Journal of Personality and Social Psychology, 17(2), 124.

Eid, M., \& Diener, E. (2001). Norms for experiencing emotions in different cultures: inter- and intranational differences. Journal of Personality and Social Psychology, 81(5), 869-885.

Ferguson, G. M., Nguyen, J., \& Iturbide, M. I. (2016). Playing up and playing down cultural identity: Introducing cultural influence and cultural variability. Cultural Diversity \& Ethnic Minority Psychology.

Geertz, C. (1973). The interpretation of cultures: Selected essays. New York: Basic Books.

Groot, A. M. B. de, \& Kroll, J. F. (2014). Tutorials in bilingualism: Psycholinguistic perspectives. Psychology Press.

Güngör, D., Bornstein, M. H., Leersnyder, J. D., Cote, L., Ceulemans, E., \& Mesquita, B. (2013). Acculturation of personality: A three-culture study of Japanese, Japanese Americans, and European Americans. Journal of CrossCultural Psychology, 44(5), 701-718. doi:10.1177/0022022112470749

Haenni Hoti, A., Heinzmann, S., Müller, M., \& Buholzer, A. (2017). Psychosocial adaptation and school success of Italian, Portuguese and Albanian students in Switzerland: Disentangling migration background, acculturation and the school context. Journal of International Migration and Integration, 18, 85-106. doi:10.1007/s12134-015-0461-x

Hasher, L., \& Zacks, R. T. (1979). Automatic and effortful processes in memory. Journal of Experimental Psychology: General, 108(3), 356-388. doi:10.1037/0096-3445.108.3.356

Hong, Y., Morris, M. W., Chiu, C., \& Benet-Martínez, V. (2000). Multicultural minds: A dynamic constructivist approach to culture and cognition. American Psychologist, 55(7), 709-720. doi:10.1037/0003-066X.55.7.709

Hong, Y., Wan, C., Sun, N., \& Chiu, C.-Y. (2007). Multicultural identities. In S. Kitayama \& D. Cohen (Eds.), Handbook of cultural psychology (pp. 323-345). New York, NY: Guilford Press. 
International Journal of Intercultural Relations, 2019 - NOT THE FINAL TYPESET VERSION

Hunt, L. M., Schneider, S., \& Comer, B. (2004). Should "acculturation” be a variable in health research? A critical review of research on US Hispanics. Social Science \& Medicine, 59(5), 973-986. doi:10.1016/j.socscimed.2003.12.009

Huynh, Q.-L., Nguyen, A.-M. D., \& Benet-Martínez, V. (2011). Bicultural identity integration. In S. J. Schwartz, K. Luyckx, \& V. L. Vignoles (Eds.), Handbook of Identity Theory and Research (pp. 827-842). Springer New York. doi:10.1007/978-1-4419-7988-9_35

Kahneman, D. (1973). Attention and effort. Englewood Cliffs, NJ: Prentice-Hall.

Kashima, Y. (2008). A social psychology of cultural dynamics: Examining how cultures are formed, maintained, and transformed. Social and Personality Psychology Compass, 2(1), 107-120. doi:10.1111/j.1751-9004.2007.00063.x

Kashima, Y., \& Gelfand, M. J. (2012). History of culture and psychology. In A. W. Kruglanski \& W. Stroebe (Eds.), Handbook of the history of social psychology (pp. 499-520). New York, NY: Psychology Press.

Kashima, Y., Laham, S. M., Dix, J., Levis, B., Wong, D., \& Wheeler, M. (2015). Social transmission of cultural practices and implicit attitudes. Organizational Behavior and Human Decision Processes, 129(Supplement C), 113-125. doi:10.1016/j.obhdp.2014.05.005

Keller, H. (2012). Cross-cultural psychology: Taking people, contexts, and situations seriously. In J. Valsiner (Ed.), The Oxford handbook of culture and psychology. Oxford, UK: Oxford University Press.

Kitayama, S., Duffy, S., Kawamura, T., \& Larsen, J. T. (2003). Perceiving an object and its context in different cultures. Psychological Science, 14(3), 201.

Kitayama, S., Karasawa, M., Curhan, K. B., Ryff, C. D., \& Markus, H. R. (2010). Independence and interdependence predict health and wellbeing: Divergent patterns in the United States and Japan. Frontiers in Psychology, 1. doi:10.3389/fpsyg.2010.00163

Kitayama, S., Mesquita, B., \& Karasawa, M. (2006). Cultural affordances and emotional experience: socially engaging and disengaging emotions in Japan and the United States. Journal of Personality and Social Psychology, 91(5), 890.

Kwan, L. Y.-Y., Yap, S., \& Chiu, C. (2015). Mere exposure affects perceived descriptive norms: Implications for personal preferences and trust. Organizational Behavior and Human Decision Processes, 129(Supplement C), 48-58. doi:10.1016/j.obhdp.2014.12.002

Lazarus, R. S., \& Folkman, S. F. (1984). Stress, appraisal, and coping. New York, NY: Springer.

Leung, A. K.-Y., Maddux, W. W., Galinsky, A. D., \& Chiu, C. (2008). Multicultural experience enhances creativity: the when and how. The American Psychologist, 63(3), 169-181. doi:10.1037/0003-066X.63.3.169

Licata, L., \& Heine, A. (2012). Introduction à la psychologie interculturelle. Bruxelles: De Boeck.

Liu, Z., \& Morris, M. W. (2014). Intercultural interactions and cultural transformation. Asian Journal of Social Psychology, 17(2), 100-103. doi:10.1111/ajsp.12047

Lopez-Class, M., Castro, F. G., \& Ramirez, A. G. (2011). Conceptions of acculturation: A review and statement of critical issues. Social Science \& Medicine, 72(9), 1555-1562. doi:10.1016/j.socscimed.2011.03.011

Luijters, K., van der Zee, K. I., \& Otten, S. (2006). Acculturation strategies among ethnic minority workers and the role of intercultural personality traits. Group Processes \& Intergroup Relations, 9(4), 561-575. doi:10.1177/1368430206067554

Lyons, A., \& Kashima, Y. (2006). Maintaining stereotypes in communication: Investigating memory biases and coherenceseeking in storytelling. Asian Journal of Social Psychology, 9(1), 59-71. doi:10.1111/j.1467-839X.2006.00184.x

Markus, H. R., \& Hamedani. (2007). Sociocultural psychology: The dynamic interdependence among self systems and social systems. In S. Kitayama \& D. Cohen (Eds.), Handbook of cultural psychology (pp. 3-39). New York: Guilford Press.

Markus, H. R., \& Kitayama, S. (1991). Culture and the self: Implications for cognition, emotion, and motivation. Psychological Review, 98(2), 224-253.

Mesquita, B. (2001). Emotions in collectivist and individualist contexts. Journal of Personality and Social Psychology, 80(1), 68-74. doi:10.1037/0022-3514.80.1.68

Mesquita, B., De Leersnyder, J., \& Jasini, A. (2017). The cultural psychology of acculturation. In S. Kitayama \& D. Cohen (Eds.), Handbook of Cultural Psychology (2nd ed.). New York, NY: Guilford Press.

Miller, J. G. (1999). Cultural psychology: Implications for basic psychological theory. Psychological Science, 10(2), 85-91. doi:10.1111/1467-9280.00113

Morling, B., \& Lamoreaux, M. (2008). Measuring culture outside the head: A meta-analysis of individualism—collectivism in cultural products. Personality and Social Psychology Review, 12(3), 199-221. doi:10.1177/1088868308318260

Morris, M. W., Chiu, C., \& Liu, Z. (2015). Polycultural psychology. Annual Review of Psychology, 66(1), 631-659. doi:10.1146/annurev-psych-010814-015001

Mourey, J. A., Lam, B. C. P., \& Oyserman, D. (2015). Consequences of cultural fluency. Social Cognition, 33(4), 308-344. doi:10.1521/soco.2015.33.4.308

Neuman, Y. (2013). Introduction to Computational Cultural Psychology. Cambridge: Cambridge University Press. doi:10.1017/CBO9781139198851

Newson, L., Richerson, P. J., \& Boyd, R. (2007). Cultural evolution and the shaping of cultural diversity. In S. Kitayama \& D. Cohen (Eds.), Handbook of cultural psychology (pp. 454-476). Guilford Press.

Nguyen, A.-M. D., \& Benet-Martínez, V. (2013). Biculturalism and adjustment: A meta-analysis. Journal of Cross-Cultural Psychology, 44(1), 122-159. doi:10.1177/0022022111435097

Norenzayan, A., Smith, E. E., Kim, B. J., \& Nisbett, R. E. (2002). Cultural preferences for formal versus intuitive reasoning. Cognitive Science, 26(5), 653-684. doi:10.1207/s15516709cog2605_4 
International Journal of Intercultural Relations, 2019 - NOT THE FINAL TYPESET VERSION

OECD. (2014). Foreign-born population [Data set]. OECD Publishing. doi:10.1787/5a368e1b-en

Oyserman, D. (2011). Culture as situated cognition: Cultural mindsets, cultural fluency, and meaning making. European Review of Social Psychology, 22(1), 164-214. doi:10.1080/10463283.2011.627187

Oyserman, D. (2017). Culture three ways: Culture and subcultures within countries. Annual Review of Psychology, 68, 435463.

Perunovic, W. Q. E., Heller, D., \& Rafaeli, E. (2007). Within-person changes in the structure of emotion: the role of cultural identification and language. Psychological Science, 18(7), 607-613. doi:10.1111/j.1467-9280.2007.01947.x

Ramírez-Esparza, N., Gosling, S. D., Benet-Martínez, V., Potter, J. P., \& Pennebaker, J. W. (2006). Do bilinguals have two personalities? A special case of cultural frame switching. Journal of Research in Personality, 40(2), 99-120. doi:10.1016/j.jrp.2004.09.001

Redfield, R., Linton, R., \& Herskovits, M. J. (1936). Memorandum for the study of acculturation. American Anthropologist, $38,149-152$.

Rudmin, F. W. (2009). Constructs, measurements and models of acculturation and acculturative stress. International Journal of Intercultural Relations, 33(2), 106-123. doi:10.1016/j.ijintrel.2008.12.001

Rudmin, F. W., \& Ahmadzadeh, V. (2001). Psychometric critique of acculturation psychology: The case of Iranian migrants in Norway. Scandinavian Journal of Psychology, 42(1), 41-56. doi:10.1111/1467-9450.00213

Ryder, A. G., Alden, L. E., \& Paulhus, D. L. (2000). Is acculturation unidimensional or bidimensional? A head-to-head comparison in the prediction of personality, self-identity, and adjustment. Journal of Personality and Social Psychology, 79(1), 49-65. doi:10.1037/0022-3514.79.1.49

Ryder, A. G., Ban, L. M., \& Chentsova-Dutton, Y. E. (2011). Towards a cultural-clinical psychology. Social and Personality Psychology Compass, 5(12), 960-975. doi:10.1111/j.1751-9004.2011.00404.x

Ryder, A. G., \& Dere, J. (2010). Book Review: Sam, D. L., \& Berry, J. W. (Eds.). (2006). The Cambridge Handbook of Acculturation Psychology. Cambridge, UK: Cambridge University Press. Journal of Cross-Cultural Psychology, 41(2), 278-283. doi:10.1177/0022022109357030

Ryder, A. G., Yang, J., Zhu, X., Yao, S., Yi, J., Heine, S. J., \& Bagby, R. M. (2008). The cultural shaping of depression: somatic symptoms in China, psychological symptoms in North America? Journal of Abnormal Psychology, 117(2), 300.

Saad, C. S., Damian, R. I., Benet-Martínez, V., Moons, W. G., \& Robins, R. W. (2013). Multiculturalism and creativity: Effects of cultural context, bicultural Identity, and ideational fluency. Social Psychological and Personality Science, 4(3), 369-375. doi:10.1177/1948550612456560

Sam, D. L., \& Berry, J. W. (2010). Acculturation: When individuals and groups of different cultural backgrounds meet. Perspectives on Psychological Science, 5(4), 472-481. doi:10.1177/1745691610373075

Saroglou, V., \& Cohen, A. B. (2011). Psychology of culture and religion: Introduction to the JCCP special issue. Journal of Cross-Cultural Psychology, 42(8), 1309-1319.

Savani, K., Morris, M. W., Naidu, N. V. R., Kumar, S., \& Berlia, N. V. (2011). Cultural conditioning: Understanding interpersonal accommodation in India and the United States in terms of the modal characteristics of interpersonal influence situations. Journal of Personality and Social Psychology, 100(1), 84.

Schwartz, S. J., Unger, J. B., Zamboanga, B. L., \& Szapocznik, J. (2010). Rethinking the concept of acculturation: Implications for theory and research. American Psychologist, 65(4), 237-251. doi:10.1037/a0019330

Schwarzenthal, M., Juang, L., Schachner, M. K., van de Vijver, A. J. R., \& Handrick, A. (2017). From tolerance to understanding: Exploring the development of intercultural competence in multiethnic contexts from early to late adolescence. Journal of Community and Applied Social Psychology, 27(5): 388-399. doi:10.1002/casp.2317

Searle, W., \& Ward, C. (1990). The prediction of psychological and sociocultural adjustment during cross-cultural transitions. International Journal of Intercultural Relations, 14(4), 449-464. doi:10.1016/0147-1767(90)90030-Z

Segall, M. H., Lonner, W. J., \& Berry, J. W. (1998). Cross-cultural psychology as a scholarly discipline: On the flowering of culture in behavioral research. American Psychologist, 53(10), 1101.

Segalowitz, N., Gatbonton, E., \& Trofimovich, P. (2009). Links between ethnolinguistic afiliation, self-rated motivation, and second language fluency. In Z. Dörnyei \& E. Ushioda (Eds.), Motivation, language identity and the L2 self (pp. 165171). Bristol, UK: Multilingual Matters.

Sheldon, K. M., Titova, L., Gordeeva, T. O., Osin, E. N., Lyubomirsky, S., \& Bogomaz, S. (2017). Russians inhibit the expression of happiness to strangers: Testing a display rule model. Journal of Cross-Cultural Psychology, 48(5), 718733. doi:10.1177/0022022117699883

Shiffrin, R. M., \& Schneider, W. (1977). Controlled and automatic human information processing: II. Perceptual learning, automatic attending and a general theory. Psychological Review, 84(2), 127-190. doi:10.1037/0033-295X.84.2.127

Shweder, R. A. (1990). Cultural psychology: What is it? In J. W. Stigler, R. A. Shweder, \& G. E. Herdt (Eds.), Cultural psychology: essays on comparative human development (pp. 1-43). Cambridge University Press.

Townsend, S. S. M., Kim, H. S., \& Mesquita, B. (2014). Are you feeling what I'm feeling? Emotional similarity buffers stress. Social Psychological and Personality Science, 5(5), 526-533. doi:10.1177/1948550613511499

Triandis, H. C. (2007). Culture and psychology: A history of the study of their relationship. In S. Kitayama \& D. Cohen (Eds.), Handbook of cultural psychology (pp. 59-76). New York, NY: Guilford Press.

Tsai, J. L., Louie, J. Y., Chen, E. E., \& Uchida, Y. (2007). Learning what feelings to desire: socialization of ideal affect through children’s storybooks. Personality \& Social Psychology Bulletin, 33(1), 17-30. doi:10.1177/0146167206292749

Vohs, K. D., Baumeister, R. F., \& Ciarocco, N. J. (2005). Self-regulation and self-presentation: Regulatory resource 
International Journal of Intercultural Relations, 2019 - NOT THE FINAL TYPESET VERSION

depletion impairs impression management and effortful self-presentation depletes regulatory resources. Journal of Personality and Social Psychology, 88(4), 632-657. doi:10.1037/0022-3514.88.4.632

Wan, C., Dach-Gruschow, K., No, S., \& Hong, Y. (2010). Self-definitional functions of culture. In A. K. Leung, C. Y. Chiu, \& Y. Hong (Eds.), Cultural Processes: A Social Psychological Perspective (pp. 111-138). New York, NY: Cambridge University Press.

Ward, C. (2001). The A,B, Cs of acculturation. In D. Matsumoto (Ed.), The handbook of culture and psychology (pp. 411445). New York, NY: Oxford University Press.

Ward, C. (2008). Thinking outside the Berry boxes: New perspectives on identity, acculturation and intercultural relations. International Journal of Intercultural Relations, 32(2), 105-114. doi:10.1016/j.ijintrel.2007.11.002

Ward, C., \& Chang, W. C. (1997). "Cultural fit”: A new perspective on personality and sojourner adjustment. International Journal of Intercultural Relations, 21(4), 525-533. doi:10.1016/S0147-1767(97)00023-0

Ward, C., \& Geeraert, N. (2016). Advancing acculturation theory and research: the acculturation process in its ecological context. Current Opinion in Psychology, 8, 98-104. doi:10.1016/j.copsyc.2015.09.021

Ward, C., \& Kus, L. (2012). Back to and beyond Berry's basics: The conceptualization, operationalization and classification of acculturation. International Journal of Intercultural Relations, 36(4), 472-485. doi:10.1016/j.ijintrel.2012.02.002

Weber, E. U., \& Morris, M. W. (2010). Culture and judgment and decision making: The constructivist turn. Perspectives on Psychological Science: A Journal of the Association for Psychological Science, 5(4), 410-419. doi:10.1177/1745691610375556

Wierzbicka, A. (1997). Lexicon as a key to ethno-sociology and cultural psychology: Patterns of "friendship" across cultures. In Understanding cultures through their key words English, Russian, Polish, German, and Japanese (pp. 32124). New York: Oxford University Press.

Yip, T. (2005). Sources of situational variation in ethnic identity and psychological well-being: a Palm Pilot study of Chinese American students. Personality \& Social Psychology Bulletin, 31(12), 1603-1616. doi:10.1177/0146167205277094

Zhang, R., \& Noels, K. A. (2013). When ethnic identities vary: Cross-situation and within-situation variation, authenticity, and well-being. Journal of Cross-Cultural Psychology, 44(4), 552-573. doi:10.1177/0022022112463604 